\title{
A NOTE ON BAPAT'S $q$-PERMANENT CONJECTURE
}

\section{LON MitchelL}

Abstract. Ravindra Bapat conjectured the $q$-permanent of a non-diagonal Hermitian positive definite matrix is a strictly increasing (in $q)$ interpolation between the determinant $(q=-1)$ and the permanent $(q=1)$. We prove that this is true for non-diagonal positive definite matrices if and only if it is true for singular positive semidefinite matrices without a zero row. Thus we conjecture the $q$-permanent of a non-diagonal Hermitian positive semidefinite matrix without a zero row is strictly increasing on $[-1,1]$. We prove this extended conjecture in the rank-one case and the 3 -by-3 case.

Mathematics subject classification (2010): 15B48, 15A15.

Keywords and phrases: $q$-permanent, positive semidefinite matrices.

\section{REFERENCES}

[1] Andelić, Milica, da Fonseca, Carlos M. And Pereira, António, The $\mu$-permanent, a new graph labeling, and a known integer sequence, Bull. Math. Soc. Sci. Math. Roumanie (N.S.), 61(109), 2018, 3, 255-262.

[2] BAPAT, R. B., Interpolating the determinantal and permanental Hadamard inequality, Linear and Multilinear Algebra, 32, 1992, 3-4, 335-337.

[3] BAPAT, R. B., Recent developments and open problems in the theory of permanents, Math. Student, 76, 2007, 1-4, 55-69 (2008).

[4] BAPAT, R. B. AND LAL, A. K., Inequalities for the q-permanent, Second Conference of the International Linear Algebra Society (ILAS) (Lisbon, 1992), Linear Algebra Appl., 197/198, 1994, 397-409.

[5] BożEJKo, MAREK AND SPEICHER, RolAnd, An example of a generalized Brownian motion, Comm. Math. Phys., 137, 1991, 3, 519-531.

[6] DA FonseCA, C. M., The $\mu$-permanent of a tridiagonal matrix, orthogonal polynomials, and chain sequences, Linear Algebra Appl., 432, 2010, 5, 1258-1266.

[7] DA FonsecA, C. M., The $\mu$-permanent revisited, Linear Multilinear Algebra, 67, 2019, 8, 1713 1714.

[8] Horn, Roger A. And Johnson, Charles R., Matrix analysis, 2nd ed., Cambridge University Press, Cambridge, 2013, xviii+643.

[9] LAL, A. K., Coxeter groups and positive matrices, 1992, Indian Statistical Institute, Delhi Center, India.

[10] LAL, A. K., Inequalities for the q-permanent. II, Linear Algebra Appl., 274, 1998, 1-16.

[11] Marcus, Marvin, The permanent analogue of the Hadamard determinant theorem, Bull. Amer. Math. Soc., 69, 1963, 494-496.

[12] DE SÁ, EdUARDo MARQUES, Linear preservers for the q-permanent, cycle q-permanent expansions, and positive crossings in digraphs, Linear Algebra Appl., 561, 2019, 228-252.

[13] DE SÁ, EdUARDO MARQUES, Noncrossing partitions, noncrossing graphs, and q-permanental equations, Linear Algebra Appl., 541, 2018, 36-53.

[14] DE SÁ, EduARdo MARques, Letter to the editor, Linear Multilinear Algebra, 67, 2019, 8, 17111712 . 